\title{
THE COMPARED COSTS OF DOMINATION LOCATION-DOMINATION AND IDENTIFICATION
}

\author{
OLIVIER HUDRY \\ LTCI, Télécom ParisTech \\ Université Paris-Saclay \\ 46 rue Barrault, 75634 Paris Cedex 13 - France \\ e-mail: olivier.hudry@telecom-paristech.fr
}

AND

\section{Antoine Lobstein}

Centre National de la Recherche Scientifique

Laboratoire de Recherche en Informatique, UMR 8623

Université Paris-Sud, Université Paris-Saclay

Bâtiment 650 Ada Lovelace, 91405 Orsay Cedex - France

e-mail: antoine.lobstein@lri.fr

\begin{abstract}
Let $G=(V, E)$ be a finite graph and $r \geq 1$ be an integer. For $v \in V$, let $B_{r}(v)=\{x \in V: d(v, x) \leq r\}$ be the ball of radius $r$ centered at $v$. A set $C \subseteq V$ is an $r$-dominating code if for all $v \in V$, we have $B_{r}(v) \cap C \neq \emptyset$; it is an $r$-locating-dominating code if for all $v \in V$, we have $B_{r}(v) \cap C \neq \emptyset$, and for any two distinct non-codewords $x \in V \backslash C, y \in V \backslash C$, we have $B_{r}(x) \cap C \neq B_{r}(y) \cap C$; it is an $r$-identifying code if for all $v \in V$, we have $B_{r}(v) \cap C \neq \emptyset$, and for any two distinct vertices $x \in V, y \in V$, we have $B_{r}(x) \cap C \neq B_{r}(y) \cap C$. We denote by $\gamma_{r}(G)$ (respectively, $l d_{r}(G)$ and $i d_{r}(G)$ ) the smallest possible cardinality of an $r$-dominating code (respectively, an $r$-locating-dominating code and an $r$-identifying code). We study how small and how large the three differences $i d_{r}(G)-l d_{r}(G), i d_{r}(G)-\gamma_{r}(G)$ and $l d_{r}(G)-\gamma_{r}(G)$ can be.
\end{abstract}

Keywords: graph theory, dominating set, locating-dominating code, identifying code, twin-free graph.

2010 Mathematics Subject Classification: 68R10, 05C90, 94C12, 94B60, 94B65. 


\section{REFERENCES}

[1] C. Berge, Graphes (Gauthier-Villars, Paris, 1983).

[2] C. Berge, Graphs (North-Holland Publishing Co., Amsterdam, 1985).

[3] N. Bertrand, Codes identifiants et codes localisateurs-dominateurs sur certains graphes, Mémoire de stage de maîtrise, ENST (Paris, France, 2001).

[4] I. Charon, O. Hudry and A. Lobstein, Possible cardinalities for identifying codes in graphs, Australas. J. Combin. 32 (2005) 177-195.

[5] I. Charon, O. Hudry and A. Lobstein, Possible cardinalities for locating-dominating codes in graphs, Australas. J. Combin. 34 (2006) 23-32.

[6] I. Charon, O. Hudry and A. Lobstein, Extremal cardinalities for identifying and locating-dominating codes in graphs, Discrete Math. 307 (2007) 356-366. doi:10.1016/j.disc.2005.09.027

[7] C.J. Colbourn, P.J. Slater and L.K. Stewart, Locating dominating sets in series parallel networks, Congr. Numer. 56 (1987) 135-162.

[8] R. Diestel, Graph Theory (Springer-Verlag, Berlin, 2005).

[9] J.F. Fink, M.S. Jacobson, L.F. Kinch and J. Roberts, On graphs having domination number half their order, Period. Math. Hungar. 16 (1985) 287-293.

doi:10.1007/BF01848079

[10] F. Foucaud, E. Guerrini, M. Kovše, R. Naserasr, A. Parreau and P. Valicov, Extremal graphs for the identifying code problem, European J. Combin. 32 (2011) 628-638. doi:10.1016/j.ejc.2011.01.002

[11] S. Gravier, R. Klasing and J. Moncel, Hardness results and approximation algorithms for identifying codes and locating-dominating codes in graphs, Algorithmic Oper. Res. 3 (2008) 43-50.

[12] S. Gravier and J. Moncel, On graphs having a $V \backslash\{x\}$ set as an identifying code, Discrete Math. 307 (2007) 432-434. doi:10.1016/j.disc.2005.09.035

[13] T.W. Haynes, S.T. Hedetniemi and P.J. Slater, Fundamentals of Domination in Graphs (Marcel Dekker, New York, 1998).

[14] M.G. Karpovsky, K. Chakrabarty and L.B. Levitin, On a new class of codes for identifying vertices in graphs, IEEE Trans. Inform. Theory 44 (1998) 599-611. doi:10.1109/18.661507

[15] A. Lobstein, Watching systems, identifying, locating-dominating and discriminating codes in graphs, a bibliography. https://www.lri.fr/ lobstein/debutBIBidetlocdom.pdf

[16] O. Ore, Theory of Graphs (American Mathematical Society, Providence, 1962). doi:10.1090/coll/038 
[17] C. Payan and N.H. Xuong, Domination-balanced graphs, J. Graph Theory 6 (1982) 23-32.

doi:10.1002/jgt.3190060104

[18] P.J. Slater, Domination and location in graphs, Research Report 93 (National University of Singapore, 1983).

Received 21 July 2017

Revised 15 February 2018

Accepted 15 February 2018 